\title{
AN ANALYSIS OF THE FAILURE OF THE COLUMNS OF A 600 METRE LENGTH OF THE HANSHIN ELEVATED EXPRESSWAY DURING THE GREAT HANSHIN EARTHQUAKE OF 17 JANUARY 1995
}

\author{
R. Park ${ }^{1}$
}

\begin{abstract}
An analysis of the failure of the reinforced concrete columns of a $600 \mathrm{~m}$ length of the Hanshin elevated expressway in Kobe which collapsed during the Great Hanshin Earthquake of 17 January 1995 is presented.
\end{abstract}

\section{INTRODUCTION}

The earthquake which caused extensive damage to the city of Kobe and the adjacent cities of Ashiya and Nishinomiya on 17 January 1995, known in the popular press as the Great Hanshin Earthquake or more formally as the Hyogo-ken Nanbu Earthquake, had a Richter magnitude of 7.2. The epicentre was located only $20 \mathrm{~km}$ from the central part of Kobe, and the focus was at a relativity shallow depth of less than $20 \mathrm{~km}$. The damage inflicted on Kobe and the adjacent cities was very severe [Park et al, 1995]. Peak horizontal ground accelerations of about $0.85 \mathrm{~g}$ were recorded.

The main urban areas of Kobe, Ashiya and Nishinomiya lie in a narrow $30 \mathrm{~km}$ long east-west strip of land between the Rokko Mountains and the sea. The developed area is only 2 to $4 \mathrm{~km}$ wide (see Figure 1). Running east-west along this developed area are four railway lines (the Trunk and Shinkansen lines operated by the Japan Railways Company and the Hanshin and Hankyo lines operated by private companies) and two multi-lane elevated expressways (the Kobe Route and Wangan Route operated by the Hanshin Expressway Public Corporation). In addition there are two multi-lane surface roads. These arterial routes are important for commuter transport within the cities and beyond, and for freight transport to and from the port of Kobe and through the cities. Some $22 \%$ of the total road freight in Japan normally passed through this narrow corridor. The port of Kobe was the largest container port in Japan. The above road and rail system, and the port, was brought to a standstill by the earthquake. The rail lines were cut and the only arterial route which remained passable after the earthquake was one of the surface road routes.

1 University of Canterbury, Christchurch, New Zealand (Fellow)

Note: The major part of the analysis given in this paper was presented by the author at the technical conference of the New Zealand Concrete Society in Auckland, August/September 1995.
Most of the severe damage to bridges was due to spans dropping off piers and to the failure of piers of elevated bridge structures. The report of the NZNSEE Reconnaissance Team on the earthquake [Park et al, 1995] gives a detailed description of the damage.

Seismic design codes for bridges specified by the Ministry of Construction in Japan have undergone successive changes through the years. A major step forward was the additional provisions introduced in the 1980 code [Japan Road Association, 1980] with the aim of enhancing the ductility of columns. In general, the elevated bridge structures designed before 1980 performed poorly during the earthquake in Kobe and adjacent cities.

This paper presents an analysis of the failure of the reinforced concrete columns which supported a $600 \mathrm{~m}$ length of the elevated Hanshin Expressway which was constructed in the $1960 \mathrm{~s}$.

\section{THE FAILURE OF THE REINFORCED CONCRETE PIERS OF THE COLLAPSED LENGTH OF THE HANSHIN EXPRESSWAY}

\subsection{The Piers}

Of considerable interest was the collapse during the earthquake of a $600 \mathrm{~m}$ length of the Kobe Route of the Hanshin Expressway shown in Figure 2. This part of the expressway was constructed in the 1960s (opened in 1969). It is shown after construction in Figure 3 and consists of concrete deck and piers. Each span is $36 \mathrm{~m}$ and was constructed of a $25 \mathrm{~m}$ "drop-in" length and an 11 $\mathrm{m}$ hammerhead supported on single column piers (see Figure 4).

The concrete columns are of circular cross section, $3.1 \mathrm{~m}$ diameter, and contain longitudinal bars in circular array in three concentric rings (see Figure 5). Each ring contains sixty $35 \mathrm{~mm}$ diameter longitudinal bars. The inner ring of longitudinal bars, containing one-third of the total area of longitudinal bars, were cut-off (terminated) at $2.5 \mathrm{~m}$ above the pile cap. The 


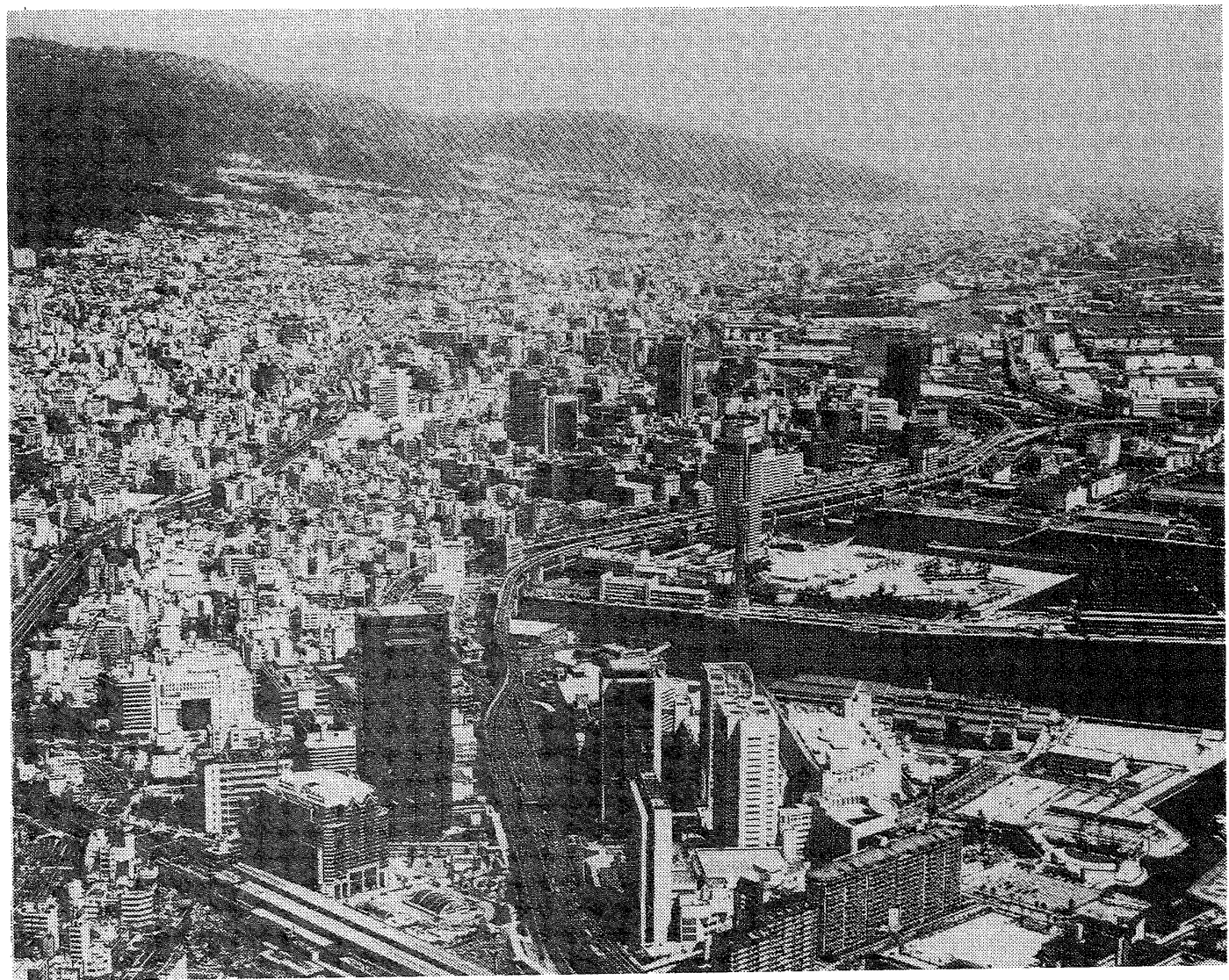

FIGURE 1 Kobe City Between the Rokko Mountains and Osaka Bay

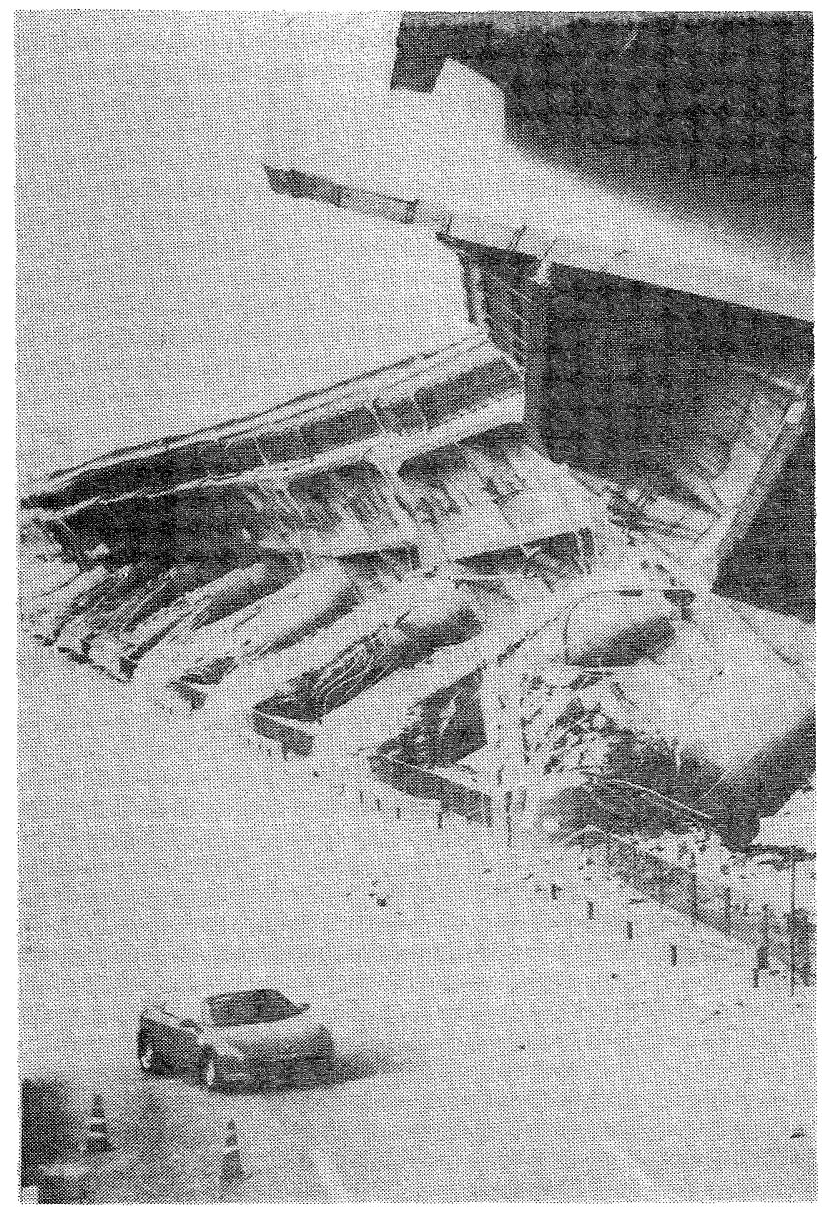

longitudinal bars in the two outer rings extended the full height of the column. The $16 \mathrm{~mm}$ diameter circular hoops were at 400 $\mathrm{mm}$ vertical spacing around the inner ring. For each of the two outer rings the $16 \mathrm{~mm}$ diameter hoops were at $200 \mathrm{~mm}$ vertical spacing for the bottom $2.5 \mathrm{~m}$ height of column above the top of the pile cap, at $300 \mathrm{~mm}$ vertical spacing for the next $4.2 \mathrm{~m}$, and at $200 \mathrm{~mm}$ vertical spacing above, around each ring.

The piers had apparently been designed for a horizontal seismic acceleration of at least $0.2 \mathrm{~g}$ using working stress design with a permitted overstress of $50 \%$.

\subsection{The Causes of Failure}

The failure of the reinforced concrete columns (see Figure 2) was evidently due to a combination of circumstances:

(a) Lack of adequate transverse reinforcement for shear resistance, for confinement of concrete, and for restraint of buckling of longitudinal reinforcement due to:

- The small quantity of the $16 \mathrm{~mm}$ diameter circular hoop reinforcement present. This meant that a substantial shear force had to be resisted by the concrete mechanisms of aggregate interlock, dowel action and across the compression zone, and that restraint against buckling of longitudinal bars and confinement of concrete was inadequate.

- Poor anchorage of the circular hoop reinforcement. The circular hoop bars were lap spliced, without hooks or the Hanshin Expressway that Collapsed. 


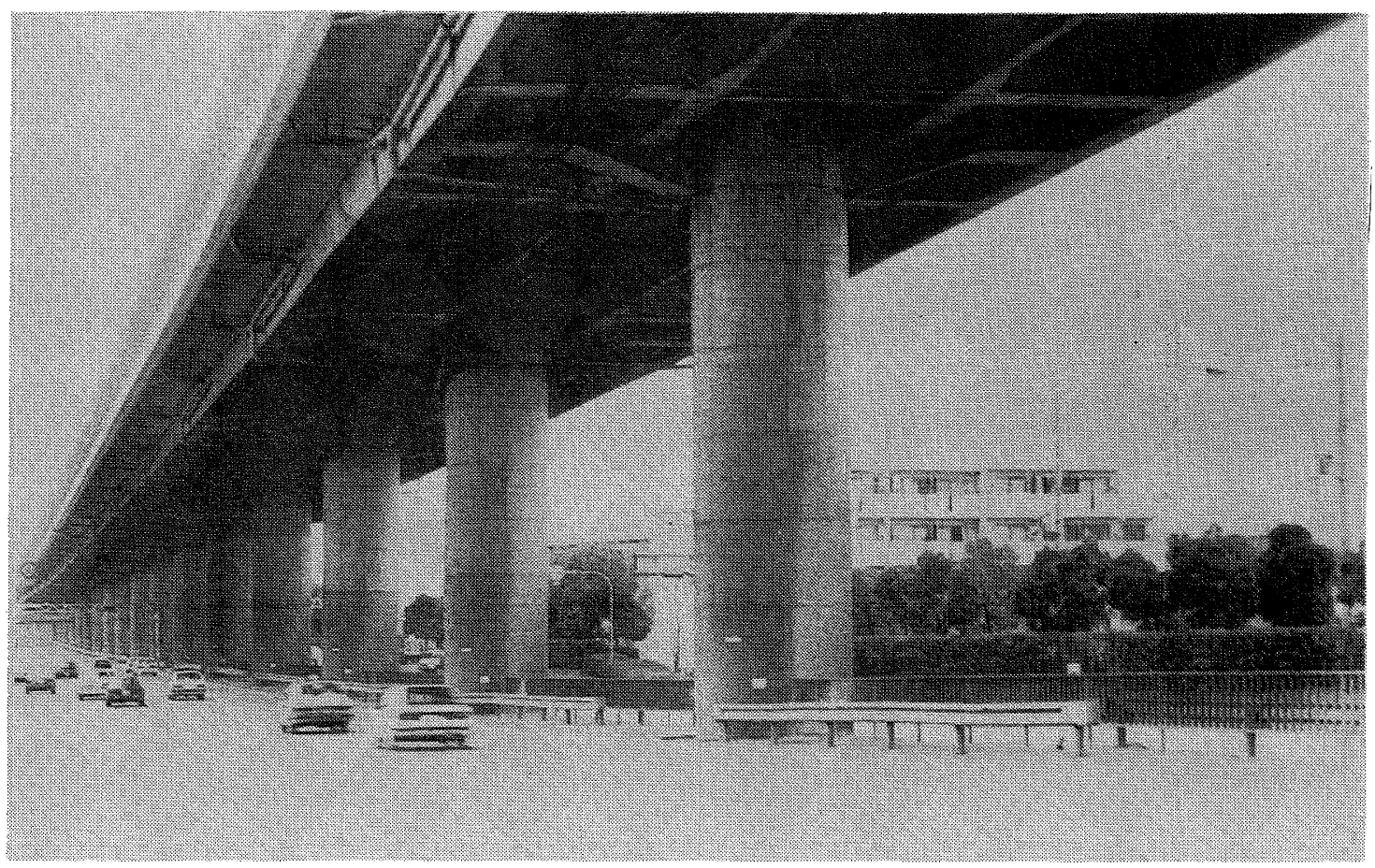

FIGURE 3 The Previous Part of the Kobe Route of the Hanshin Expressway (Figure 2) as it Looked after Construction in the 1960s.

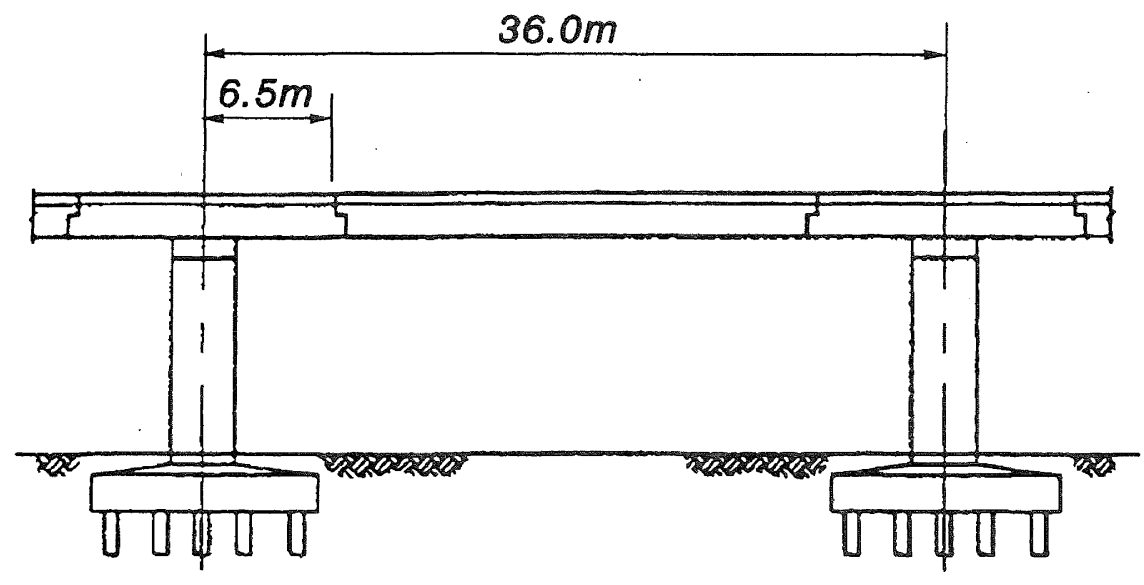

Part Elevation

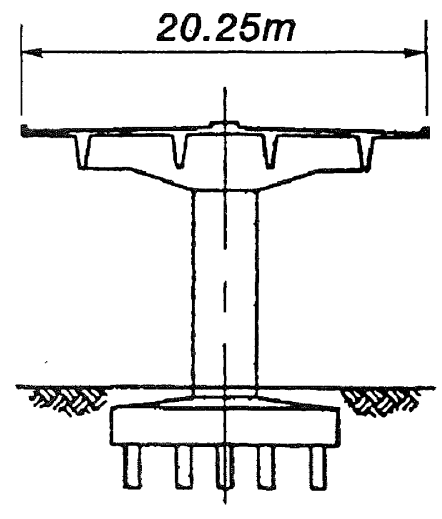

Section A-A

FIGURE 4 Elevation and Cross Section of Collapsed Portion of the Hanshin Expressway.

welding in the cover concrete, and anchorage would have been lost when the cover concrete spalled.

(b) Poor performance of the $35 \mathrm{~mm}$ diameter longitudinal reinforcement due to:

- Butt welds of the reinforcement which in many cases fractured in a brittle manner. The butt welds were observed to be not staggered but to be all at the same level.
- The termination of one-third of the longitudinal reinforcement at $2.5 \mathrm{~m}$ above the pile cap. This cut-off apparently followed a bending moment diagram without allowance for the spread of steel yielding up the column due to diagonal tension cracking (that is, the Tjd effect was neglected), leading to severe cracking due to yielding of steel at the cut-off section $2.5 \mathrm{~m}$ above the pile cap. 

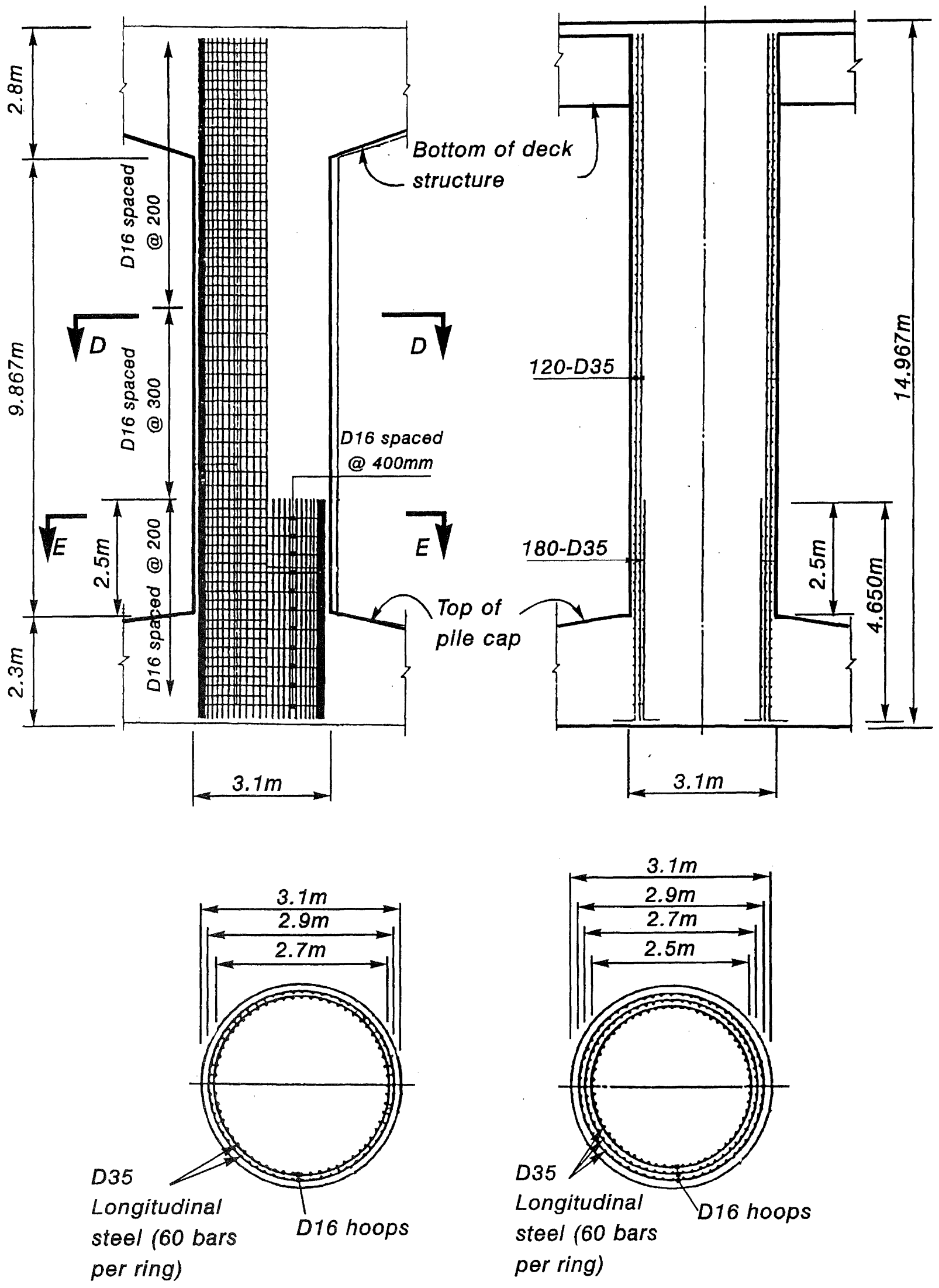

SECTION D-D

SECTION E-E

FIGURE 5 Reinforcement in Typical Columns of Collapsed Portion of the Hanshin Expressway. 
The failure of the columns would probably have involved the following sequence of events:

(a) Flexural and diagonal tension cracking occurring during the acceleration pulses in each direction leading to crushing and spalling of the cover concrete in the region of the column above the pile cap and to the spread of yielding of the longitudinal reinforcement up the column, and to degradation of the concrete shear resisting mechanisms (see Figure 6), then to;

(b) Widening of diagonal tension cracks due to inadequate shear resistance from the circular hoops, particularly when anchorage of the lap splices was lost due to crushing of cover concrete, and to yielding at sections of cut-off of longitudinal bars, and finally to;

(c) Failure in shear made particularly brittle by the failure of the butt welds of the longitudinal bars at the top of the inclined crack (see Figure 7).

It is to be noted that failure of hoops with lap splices in the cover concrete was a common feature also of bridge columns during the 1971 San Fernando Earthquake [Jennings, 1971].

\section{ANALYSIS OF THE FAILURE OF THE COLLAPSED REINFORCED CONCRETE COLUMNS OF THE HANSHIN EXPRESSWAY}

\subsection{Analysis Procedure}

The failure of the columns can be analysed by first determining the axial load in the columns from the dead weight of the structure and calculating the associated probable flexural strength of the columns at the critical sections at that axial load. Then the shear force imposed on the column when that flexural strength was reached can be calculated and compared with the available shear strength of the columns calculated using current procedures. The anchorage of the circular hoops would have been lost when the cover concrete crushed and spalled. The curvature of the column at that stage can be calculated and compared with the likely imposed curvature to check whether crushing and spalling of the cover concrete was likely.

\subsection{Column Data}

The column dimensions and reinforcement are shown in Figure 5. The strength of the materials assumed will be those provided by Professor S Ikeda of the Yokohama National University (private communication dated 2 May 1995), being the measured data obtained by the Ministry of Construction after the earthquake:

Steel: Longitudinal reinforcement $\mathrm{D} 35$

Traverse reinforcement D16

$$
A_{b}=957 \mathrm{~mm}^{2}, f_{y}=349 \mathrm{MPa}
$$

where $A_{b}=$ bar area and

$$
A_{b}=199 \mathrm{~mm}^{2}, f_{y t}=350 \mathrm{MPa}
$$

$\mathrm{f}_{\mathrm{y}}$ or $\mathrm{f}_{\mathrm{yt}}=$ average value of the yield strength.

Concrete: $\quad$ Measured from column $\mathrm{f}_{\mathrm{c}}=41.3 \mathrm{MPa}$

Measured from debris $f_{c}=32.1 \mathrm{MPa}$

where $f_{c}=$ compressive strength obtained from cores.
Assuming that the cores from the column are more reliable and that the core strength is 0.85 of the cylinder strength $f_{c}{ }^{\prime}$, the probable cylinder strength is:

$$
\mathrm{f}_{\mathrm{c}}{ }^{\prime}=49 \mathrm{MPa}
$$

This is a reasonable probable $f_{c}{ }_{c}$ for almost 30 year old concrete which had a specified compressive strength of $27.5 \mathrm{MPa}$.

\subsection{Column Axial Load}

The weight of the bridge superstructure was estimated from the dimensions of the superstructure and columns. The dead load was estimated to cause an axial compressive load at the bottom of each column of $\mathrm{N}^{*}=11,000 \mathrm{kN}$.

Hence the axial load ratio is

$$
\frac{N^{*}}{f_{c}^{\prime} A_{g}}=\frac{11,000,000}{49 \times 7,544,000}=0.0298
$$

where $\mathrm{A}_{\mathrm{g}}=$ gross area of the column.

\subsection{Probable Flexural Strength}

The probable flexural strength of the column sections were calculated by moment-curvature analysis using an available computer program [King, 1986]. The stress-strain curve for concrete is based on the model due to Mander et al [1988]. In this calculation it was assumed that at the flexural strength the concrete extreme fibre compressive strain was 0.004 , the confinement of the concrete core was nominal and no strain hardening of the steel reinforcement occurred.

The area of longitudinal reinforcement in the column section at the top of the pile cap is $180 \times 957=172,300 \mathrm{~mm}^{2}$ on a circle of mean diameter $2,633 \mathrm{~mm}$, and at the section of bar cut-off $2.5 \mathrm{~m}$ above the top of the pile cap is $120 \times 957=114,800$ $\mathrm{mm}^{2}$ on a circle of mean diameter $2,733 \mathrm{~mm}$. For the above axial load, steel areas and positions, and known material properties, the probable flexural strength of the column $M_{p}$ can be shown to be:

At the section at the top of the pile cap

$$
\mathrm{M}_{\mathrm{p}}=83,490 \mathrm{kNm}
$$

At the section of bar cut-off

$$
\mathrm{M}_{\mathrm{p}}=63,070 \mathrm{kNm}
$$

\subsection{Imposed Shear Force}

Examination of a limited number of drawings of the bridge piers shows that the clear height of the column varies between 9.43 and $12.35 \mathrm{~m}$. The column in Figure 5 has a clear height of $9.87 \mathrm{~m}$ and will be analysed. The smallest column height will result in the greatest shear force. The centre of mass is estimated to be at $1.1 \mathrm{~m}$ below the top of the deck, which makes some allowance for the weight of the column. Hence for the pier of Figure 5 the centre of mass is $12 \mathrm{~m}$ above the top of the pile cap (see Figure 8). Therefore the imposed horizontal shear forces associated with the probable flexural strength being attained are:

If the critical section of the column is at the top of the pile cap

$$
\mathrm{V}^{*}=83,490 / 12=6,960 \mathrm{kN}
$$




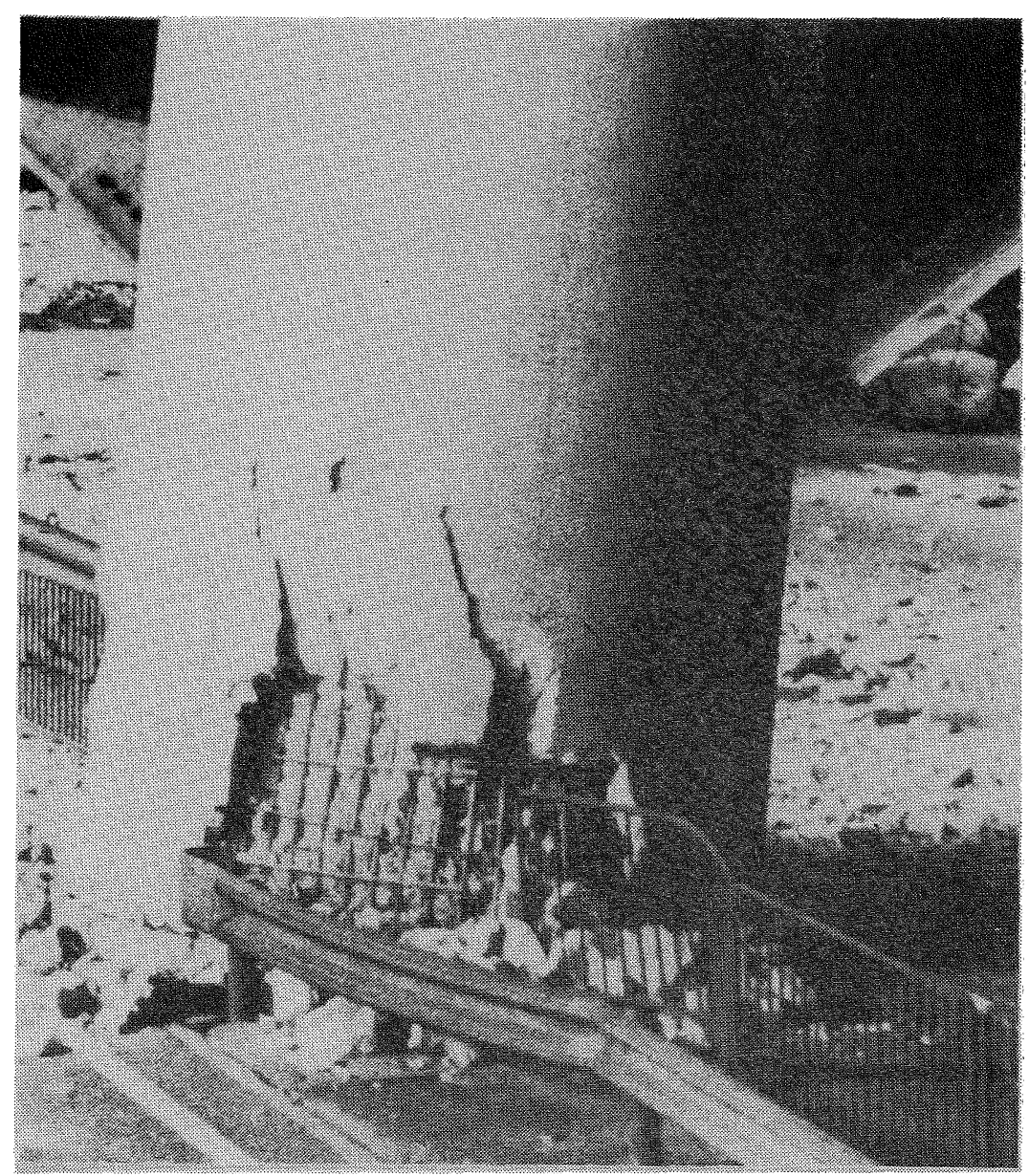

FIGURE 6 Column of Hanshin Expressway Near Collapse.

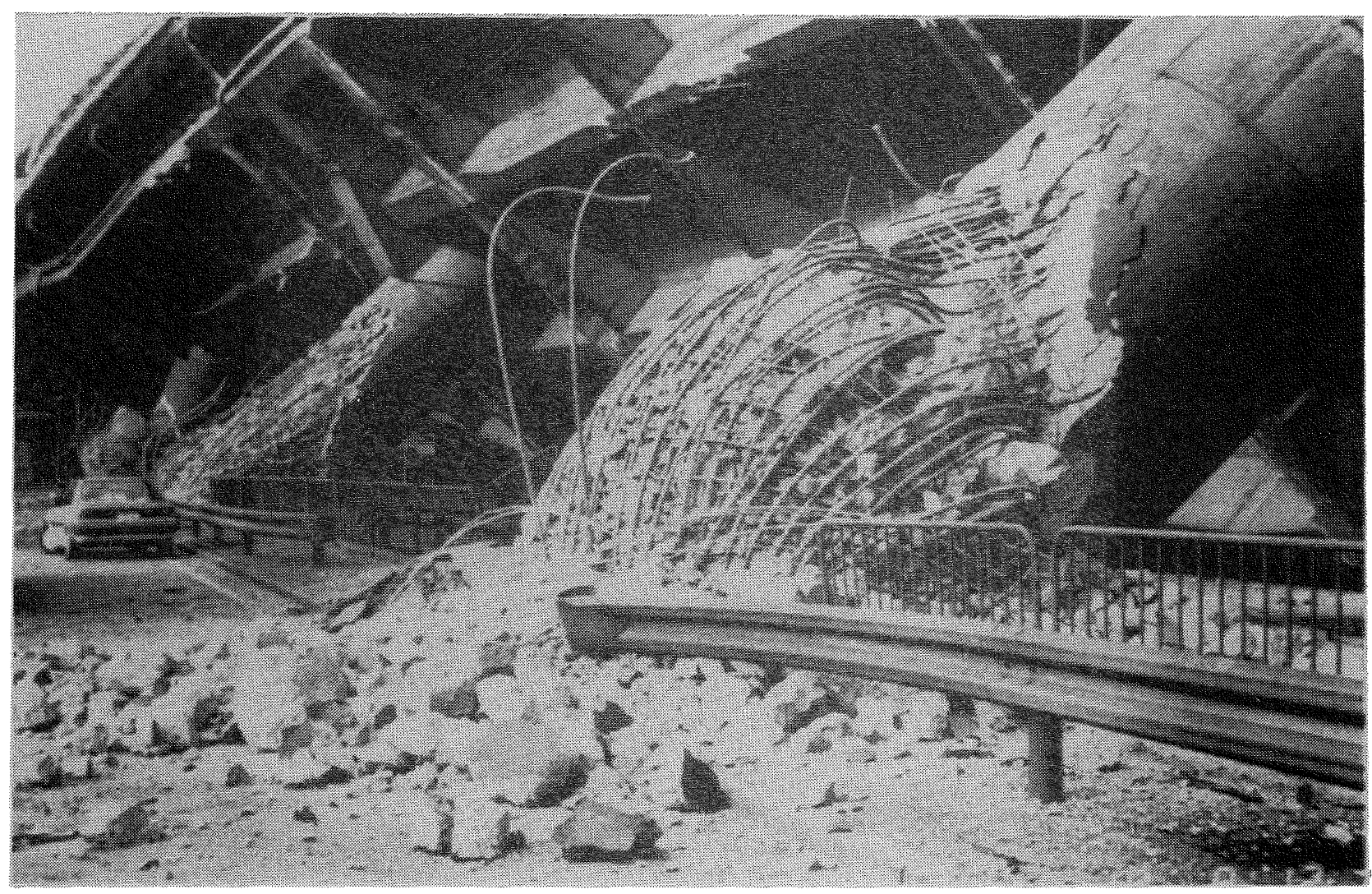

FIGURE 7 Column of Hanshin Expressway After Collapse. 
If the critical section of the column is at $2.5 \mathrm{~m}$ above the pile cap at the section of bar cut-off

$$
\mathrm{V}^{*}=63,070 / 9.5=6,640 \mathrm{kN}
$$

Hence critical $\mathrm{V}^{*}=6,640 \mathrm{kN}$

This calculation also shows that, according to the bending moment diagram of Figure 8, the critical section for flexure is at $2.5 \mathrm{~m}$ above the pile cap at the section of bar cut-off. However, the section at the column base is close to being critical.

It has been pointed out to the author (Professor MJN Priestley, University of California, San Diego, personal communication) that the critical section in the cut-off region could be taken below the section of bar cut-off (for example, $1.5 \mathrm{~m}$ below) to take account the tension shift effect as a result of the diagonal tension cracking. This would increase the length of column used in the calculation of $\mathrm{V}^{*}$, due to the probable flexural strength being reached in the cut-off region, from $9.5 \mathrm{~m}$ to 11.0 $\mathrm{m}$, thus reducing the value of $\mathrm{V}^{*}$. This refinement has not been included in the above calculation. If included it would reduce the value of $\mathrm{V}^{*}$ by $14 \%$.

Note also that the rotational inertia of the bridge deck during the response of the bridge structure to seismic shaking will mean that the bending moment at the top at the centre of mass is not exactly zero and hence that the gradient of the bending moment diagram may be different from that shown in Figure 8. That is, the gradient of the bending moment diagram will change (both increase and decrease) during various instants of the earthquake. This change in gradient will effect on the shear force induced in the columns. Dynamic analysis is required to determine whether the change in moment gradient from that shown in Figure 8 is significant. It is notable that the critical section for flexure was actually observed to be at the column base (see Figure 6) rather than in the region of bar cut-off above, which is contrary to that slightly favoured by the above calculation.

\subsection{Probable Shear Strength}

The probable shear strength of the column is:

(a) According to the New Zealand concrete design standard NZS 3101:1995 [Standards New Zealand, 1995], in potential plastic hinge regions the shear resisted by the concrete mechanisms $V_{c}$ is taken as zero when $\mathrm{N}^{*} / \mathrm{f}_{\mathrm{c}}{ }^{\prime} \mathrm{A}_{\mathrm{g}} \leq$ 0.1 . Hence for the column the probable shear strength is due only to the shear reinforcement crossing an assumed $45^{\circ}$ crack, and is

$$
\mathrm{V}_{\mathrm{p}}=\frac{\pi}{2} \mathrm{~A}_{\mathrm{sp}} \mathrm{f}_{\mathrm{yt}} \frac{\mathrm{d}^{\prime \prime}}{\mathrm{s}}
$$

where $\mathrm{A}_{\mathrm{sp}}=$ area of circular hoop bar, $\mathrm{f}_{\mathrm{yt}}=$ probable yield strength of circular hoop steel, $\mathrm{d}^{\prime \prime} \stackrel{\text { diameter of }}{=}$ circular hoop and $s=$ vertical spacing of circular hoops. For each column $d^{\prime \prime} / s$ represents the number of circular hoops intercepted by a $45^{\circ}$ crack at the bottom of the column; that is, over a height of $2.70 \mathrm{~m}$ in the potential plastic hinge region. This number is 32 .

Hence if the hoops are effectively anchored:

$$
\mathrm{V}_{\mathrm{p}}=\frac{\pi}{2} \times 199 \times 350 \times 32 \mathrm{~N}=3,500 \mathrm{kN}
$$

Alternatively, if the hoops are not effectively anchored, $\mathrm{V}_{\mathrm{p}}=0$.

Clearly, $\mathrm{V}_{\mathrm{p}}<\mathrm{V}^{*}$ and hence according to NZS 3101:1995 shear failure will occur, regardless of whether the hoops are effectively anchored or not.

(b) According to Priestley et al [1993] the probable shear strength, as determined from extensive laboratory testing conducted in recent years, can be estimated from

$$
\begin{aligned}
\mathrm{V}_{\mathrm{p}}=\mathrm{V}_{\mathrm{c}}+\mathrm{V}_{\mathrm{s}}+\mathrm{V}_{\mathrm{n}} \\
\text { where } \quad \mathrm{V}_{\mathrm{c}}=0.8 \mathrm{~A}_{\mathrm{g}} \mathrm{k} V_{\mathrm{f}_{\mathrm{c}}}{ }^{\prime}
\end{aligned}
$$

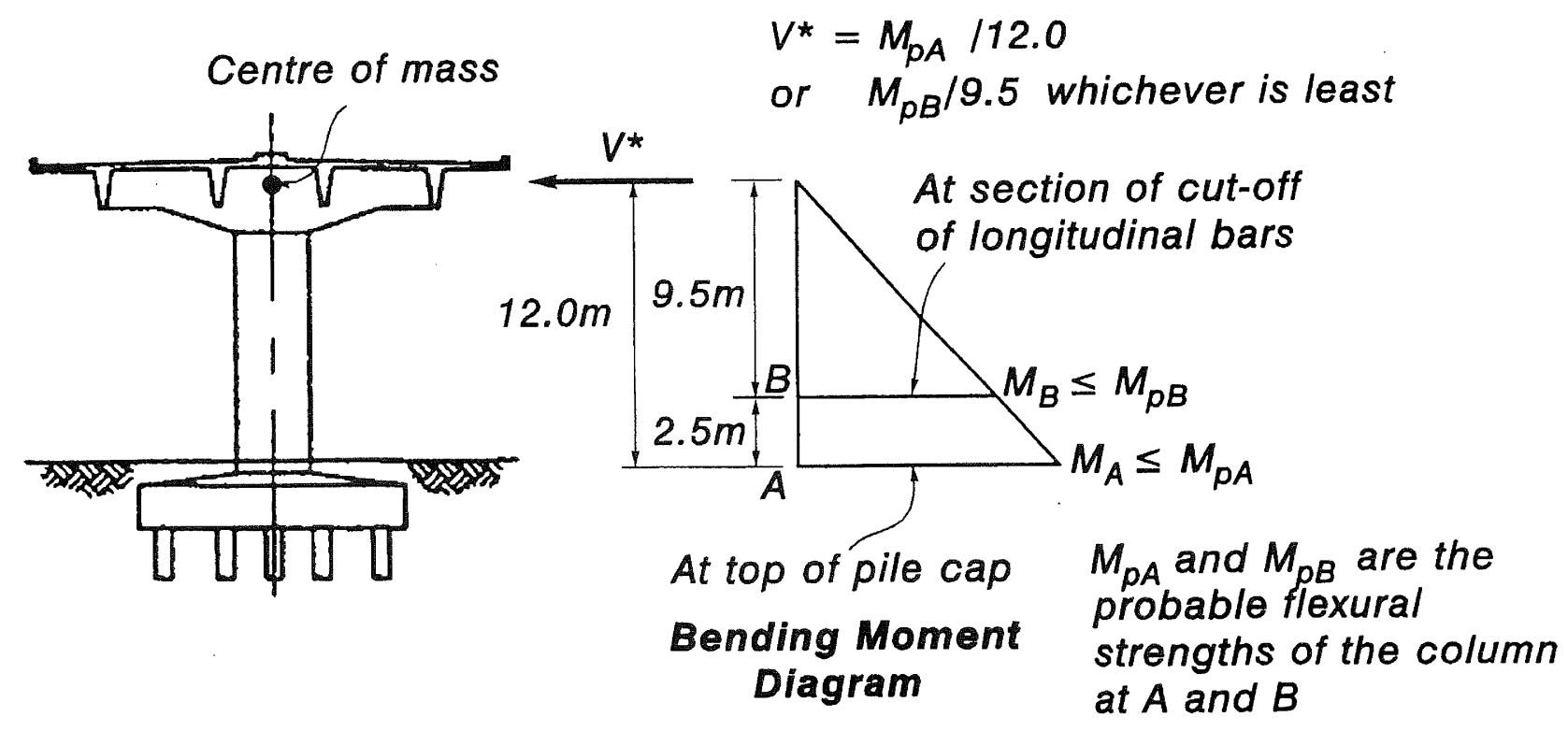

FIGURE 8 Transverse Force $V^{*}$ Acting at Centre of Mass at Stage of Reaching the Probable Flexural Strength of the Column 
where

$$
\begin{aligned}
\mathrm{k} & =0.29 \text { for } \mu_{\phi} \leq 1 \\
& =0.10 \text { for } \mu_{\phi} \geq 5
\end{aligned}
$$

and varies linearly between 0.29 and 0.10 for $\mu_{\phi}$ in the range 1 to 5 for biaxial loading, where $\mu_{\phi}$ is the curvature ductility factor demand.

Also

$$
\mathrm{V}_{\mathrm{s}}=\frac{\pi}{2} \mathrm{~A}_{\mathrm{sp}} \mathrm{f}_{\mathrm{yt}} \frac{\mathrm{d}^{\prime \prime}}{\mathrm{s}} \cot 30^{\circ}
$$

which assumes that the critical diagonal tension crack is at $30^{\circ}$ to the longitudinal axis of the column. For each column d" $\cot 30^{\circ} / \mathrm{s}$ is the number of hoops intercepted by the crack inclined at $30^{\circ}$ to the vertical axis at the bottom of the column; that is, over a height of $4.68 \mathrm{~m}$. This number is 46 .

Also

$$
\mathrm{V}_{\mathrm{n}}=\mathrm{N}^{*} \tan \alpha
$$

where for a cantilever column $\alpha$ is the angle between the longitudinal axis of the column and the straight line between the centroid of the column section at the top and the centroid of the concrete compression forces of the column section at the base. For the column analysed, tan $\alpha$ is approximately equal to $1.12 / 12=0.0933$

Hence assuming that $\mu_{\phi} \geq 5$, and that the hoops are effectively anchored:

$$
\begin{aligned}
\mathrm{V}_{\mathrm{p}} & =0.8 \times 8,169,000 \times 0.1 \sqrt{49} \\
& +\frac{\pi}{2} \times 199 \times 350 \times 46 \\
& +10,000,000 \times 0.0933 \mathrm{~N} \\
& =4,575+5,030+933 \\
& =10,538 \mathrm{kN}
\end{aligned}
$$

Alternatively, if the hoops are not effectively anchored:

$$
\mathrm{V}_{\mathrm{p}}=4,575+933=5,508 \mathrm{kN}
$$

Since $V^{*}=6,640 \mathrm{kN}$ is part way between these two values for $V_{p}$ it is clear that according to Priestley et al the column will not fail in shear if the hoops are effectively anchored, but will not fail if the anchorage is effective.

It is of concern that such differences still exist in the calculation of shear strength by different approaches. Nevertheless it is clear that because of poor anchorage of the circular hoops the shear strength of the columns was inadequate.

\subsection{Potential Plastic Hinge Region}

According to NZS 3101:1995 [Standards New Zealand, 1995], for low axial load ratios $\left(\mathrm{N}^{*}<0.25 \mathrm{f}_{\mathrm{c}}{ }^{\prime} \mathrm{A}_{\mathrm{g}}\right)$ the potential plastic hinge region at the bottom of the column is over a length of either one column diameter or where the moment exceeds 0.8 of the adjacent end moment, whichever is greater. That is, for the column considered the length would be either $3.1 \mathrm{~m}$ or 0.2 $x 12=2.4 \mathrm{~m}$. Therefore the potential plastic hinge length is $3.1 \mathrm{~m}$. Over this region the shear resisted by the concrete mechanisms $V_{c}$ is assumed to be zero according to NZS 3101:1995.

\subsection{Transverse Reinforcement for Concrete Confinement and Restraint Against Buckling of Longitudinal Reinforcement}

NZS 3101:1995 [Standards New Zealand, 1995] has requirements for transverse reinforcement to confine the compressed concrete and to restrain the longitudinal bars against buckling in potential plastic hinge regions.

According to NZS 3101:1995 the vertical spacing of hoops is not permitted to exceed the smaller of six longitudinal bar diameters or one quarter of the column diameter. Therefore, for the column considered the spacing is not to exceed either 6 x $35=210 \mathrm{~mm}$ or $3100 / 4=775 \mathrm{~mm}$; that is, $210 \mathrm{~mm}$ is the critical spacing. The spacing of hoops in the bottom $2.5 \mathrm{~m}$ of the column considered is $200 \mathrm{~mm}$, increasing to $300 \mathrm{~mm}$ above. Hence this NZS 3101: 1995 requirement is satisfied over most of the potential plastic hinge length

NZS 3101:1995 also has equations for determining the amount of transverse reinforcement needed to prevent buckling of longitudinal bars and for confining the compressed concrete. For columns with low axial load ratios (approximately $\mathrm{N}^{*}<$ $0.3 \mathrm{f}_{\mathrm{c}}{ }^{\prime} \mathrm{A}_{\mathrm{g}}$ ) the requirement for the prevention of bar buckling is more critical than the requirement for concrete confinement. For prevention of bar buckling for columns with circular hoops NZS 3101:1995 requires:

$$
\mathrm{p}_{\mathrm{s}}=\frac{4 \mathrm{~A}_{\mathrm{sp}}}{\mathrm{sd}^{\prime \prime}} \geq \frac{\mathrm{A}_{\mathrm{st}}}{110 \mathrm{~d}^{\prime \prime}} \frac{\mathrm{f}_{\mathrm{y}}}{\mathrm{f}_{\mathrm{yt}}} \frac{1}{\mathrm{~d}_{\mathrm{b}}}
$$

where $\mathrm{p}_{\mathrm{s}}=$ ratio of volume of transverse reinforcement around outer ring of vertical column bars to volume of concrete core, $\mathrm{A}_{\mathrm{sp}}=$ area of circular hoop bar, $\mathrm{A}_{\mathrm{st}}=$ total area of that ring of column bars, $s=$ spacing of circular hoops, $d^{\prime \prime}=$ diameter of circular hoops, $f_{y}=$ yield strength of longitudinal bars, $\mathrm{f}_{\mathrm{yt}}=$ yield strength of transverse bars, and $d_{b}=$ diameter of longitudinal bars.

Now from Eq. 6 it is required that

$$
\frac{A_{\text {sp }} d_{b}}{s} \geq \frac{A_{s t} f_{y}}{440 f_{y t}}
$$

Hence for the column considered it is required that

$$
\frac{A_{s p} d_{b}}{s} \geq \frac{57,400 \times 349}{440 \times 350}=131 \mathrm{~mm}^{2}
$$

Since $16 \mathrm{~mm}$ diameter circular hoops at a spacing of $200 \mathrm{~mm}$ were used in the column, the $A_{s p} d_{b}$ /s for the column as built is $199 \times 16 / 200=15.9 \mathrm{~mm}^{2}$. Hence the above NZS 3101:1995 requirement was not met. To meet it would mean reducing the spacing and/or increasing the area of circular hoop reinforcement substantially

For example, maintaining the spacing at $200 \mathrm{~mm}$ would mean using $32 \mathrm{~mm}$ diameter circular hoops.

Note that for large diameter columns the required $A_{s p} d_{b} / s$ becomes large due to the large $A_{\mathrm{st}}$ to be laterally restrained (see Eq. 7). This may lead to some cross ties being needed in large circular columns as well as circular hoops or spirals.

\subsection{Available Ductility of the Column}

The moment-curvature analysis of the column section at the base of the column indicated that when the extreme fibre concrete 
compressive strain reached 0.005 the neutral axis depth of the column was $c=678 \mathrm{~mm}$. An extreme fibre concrete compressive stress of 0.005 can be taken as about the strain at which crushing and spalling of the cover concrete occurs, $\varepsilon_{\mathrm{sp}}$, as found from previous column tests [Priestley and Park, 1987; Watson and Park, 1994]. Crushing and spalling of the cover concrete would lead to the sequence of events, including the loss of anchorage of the shear reinforcement resulting in failure, as described in Section 2.2. Therefore the available ultimate curvature of the column can be taken as:

$$
\begin{aligned}
\phi_{\mathrm{u}} & =\varepsilon_{\mathrm{sp}} / \mathrm{c} \\
& =0.005 / 678=7.37 \times 10^{-6} 1 / \mathrm{mm}
\end{aligned}
$$

The curvature at first yield of the column can be defined as:

$$
\phi_{\mathrm{y}}=\frac{\mathrm{M}_{\mathrm{p}}}{\mathrm{E}_{\mathrm{c}} \mathrm{I}_{\mathrm{e}}}
$$

where $M_{p}=$ probable flexural strength; $E_{c}=$ modulus of elasticity of concrete, which according to NZS 3101:1995 for $\mathrm{f}_{\mathrm{c}}^{\prime}=49 \mathrm{MPa}$ is $\mathrm{E}_{\mathrm{c}}=30,100 \mathrm{MPa}$; and $\mathrm{I}_{\mathrm{e}}=$ effective second moment of area of the column section, which according to the commentary of NZS 3101:1995 can be assessed to be about $0.45 \mathrm{I}_{\mathrm{g}}$ allowing for cracking, where $\mathrm{I}_{\mathrm{g}}=$ gross second moment of area, giving $\mathrm{I}_{\mathrm{e}}=0.45 \times \pi$ $\mathrm{x} 3.1^{4} / 64=2.039 \mathrm{~m}^{4}$.

$$
\therefore \phi_{\mathrm{y}}=\frac{83,490 \times 10^{-6}}{30,100 \times 2.039}=1.36 \times 10^{-6} 1 / \mathrm{mm}
$$

Hence the available curvature ductility factor at the stage of loss of the cover concrete at the base of the column is:

$$
\phi_{\mathrm{u}} / \phi_{\mathrm{y}}=7.37 / 1.36=5.42
$$

Now the equivalent plastic hinge of the column according to Priestley and Park, 1987 is:

$$
\ell_{\mathrm{p}}=0.08 \ell+12 \mathrm{~d}_{\mathrm{b}}
$$

where $\ell=$ distance from critical section for flexure to the centre of mass $=12 \mathrm{~m}$ if critical section is taken to be at the column base, and $\mathrm{d}_{\mathrm{b}}=$ diameter of longitudinal bars $=$ $35 \mathrm{~mm} \therefore \ell_{\mathrm{p}}=0.08 \times 12+12 \times 0.35=1.17 \mathrm{~m}$.

The available displacement ductility factor for a cantilever column with seismic force acting at the centre of mass at the top is according to Park and Paulay [1975]:

$$
\mu=\frac{\Delta_{\mathrm{u}}}{\Delta_{\mathrm{y}}}=1+\left(\frac{\phi_{\mathrm{u}}}{\phi_{\mathrm{y}}}-1\right) \frac{\ell_{\mathrm{p}}\left(\ell-0.5 \ell_{\mathrm{p}}\right)}{\ell^{2} / 3}
$$

where $\Delta_{\mathrm{u}}=$ ultimate horizontal displacement and $\Delta_{\mathrm{y}}=$ horizontal displacement at first yield, both measured at the centre of mass.

$$
\begin{aligned}
\therefore \mu & =1+(5.42-1) \frac{1.17(12-1.17 / 2)}{12^{2} / 3} \\
& =2.20
\end{aligned}
$$

Hence the bridge columns had very limited available displacement ductility before crushing and spalling of the concrete cover occurred.

\subsection{Ductility Demand Imposed by the Earthquake}

The horizontal inertia force at the stage when the probable flexural strength is reached (at least $6,640 \mathrm{kN}$ ) is $60 \%$ of the weight of the structure $(11,000 \mathrm{kN})$, implying that a horizontal earthquake pulse causing at least $0.6 \mathrm{~g}$ horizontal acceleration at the centre of mass was needed to cause the column to reach its probable flexural strength.

A greater elastic response acceleration than $0.6 \mathrm{~g}$ was necessary when the column was responding inelastically to cause it to reach the available displacement ductility factor of 2.2 (see Figure 9). If $\Delta_{\mathrm{e}}=\Delta_{\mathrm{u}}$ is assumed in Figure 9 (that is, equal displacement concept) it is evident that $\mathrm{V}_{\mathrm{e}}=2.2 \mathrm{~V}_{\mathrm{y}}$, where $\mathrm{V}_{\mathrm{e}}$ $=$ inertia force for elastic response and $\mathrm{V}_{\mathrm{y}}=$ inertia force for inelastic response when the strength of the column is reached. That is, the elastic response acceleration necessary to collapse the structure was at least $2.2 \times 0.6 \mathrm{~g}=1.32 \mathrm{~g}$ at the centre of mass.

The natural period of vibration of the structure, $T=2 \pi / \mathrm{M} / \mathrm{K}$ assuming no foundation flexibility, can be calculated as follows. The stiffness $\mathrm{K}$ (horizontal force per unit displacement of mass $M$ relative to the column base $)$ is given by $3 \mathrm{E}_{\mathrm{c}} \mathrm{I}_{\mathrm{e}} / \ell^{3}=(3 \mathrm{x}$ $30,100 \times 2.039) / 12^{3}=106.6 \mathrm{MN} / \mathrm{m}$.

$$
\therefore \mathrm{T}=2 \pi \sqrt{11 /(9.81 \times 106.6)}=0.64 \text { seconds. }
$$

Elastic response spectra for the Kobe JMA site, relatively near to the collapsed bridge, have been calculated by Somerville
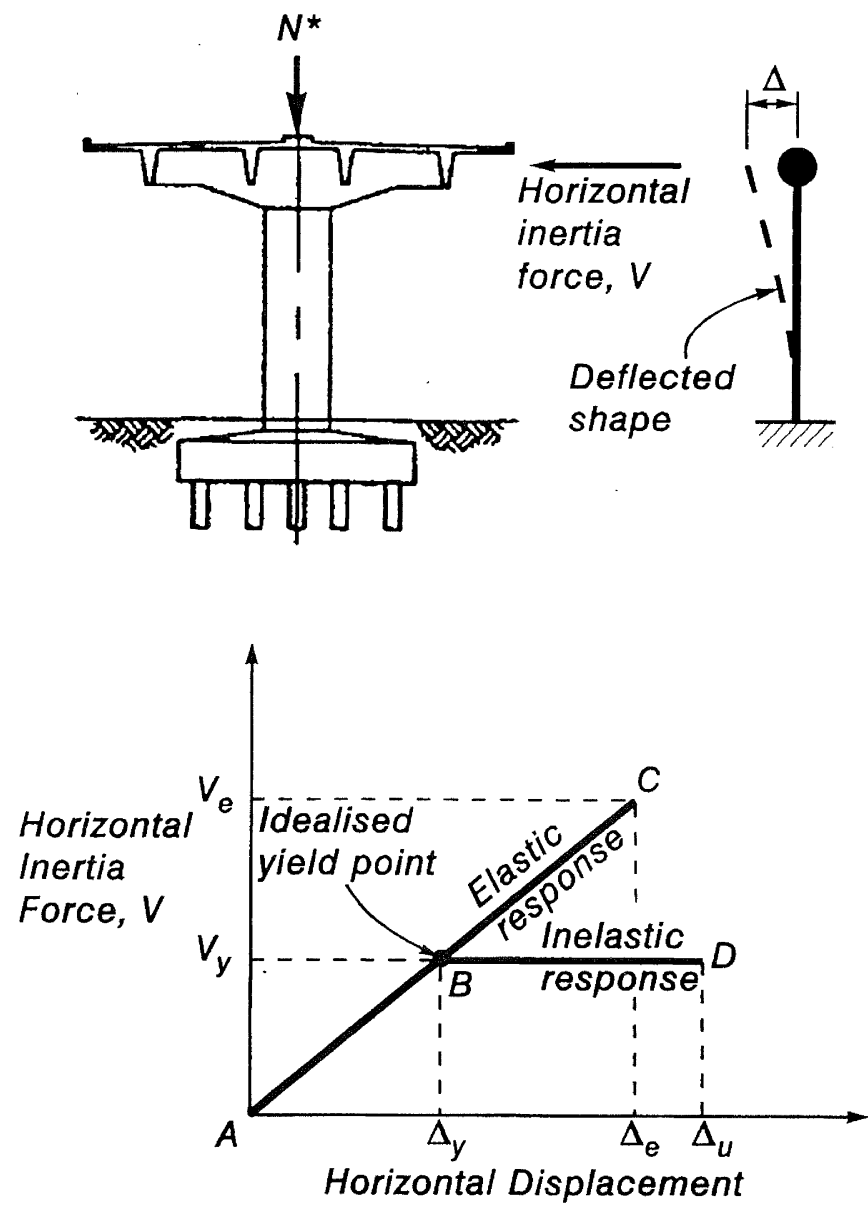

FIGURE 9 Bridge Column with Elastic and Inelastic Response to Horizontal Seismic Forces 
[1996] assuming 5\% viscous damping (see Figure 10). This direction in which the bridge fell, transverse to the longitudinal axis of the bridge, is close to the direction of the fault-normal component shown in Figure 10. It is evident from Figure 10 that in this direction horizontal elastic response accelerations of at least $2 \mathrm{~g}$ could have occurred over a broad period range of 0.3 to 1.0 seconds. Hence the pier columns would have been shaken to well beyond their level of available ductility, resulting in collapse.

\section{CONCLUSIONS}

1 Shear failure of the reinforced concrete columns of the collapsed $600 \mathrm{~m}$ length of the Kobe route of the Hanshin Expressway during the severe earthquake in Kobe, Japan on 17 January 1995 was due to a combination of circumstances; namely, the small quantity of circular hoop reinforcement, the poor anchorage of that reinforcement, the fracture of brittle butt welds of the longitudinal reinforcement, and the early termination of one-third of the longitudinal reinforcement. The main cause of failure was the poor anchorage of the ends of the circular hoops as a result of being lap spliced in the cover concrete, rather than being either welded together or hooked around the longitudinal bars. Hence when the cover concrete crushed and spalled the anchorage of the hoop reinforcement was lost and that reinforcement became ineffective.

2 It is evident that the design shear force of bridge columns should be calculated as the maximum likely value which is associated with the flexural strength of the column. The design of the quantity of well anchored shear reinforcement to resist that shear force should take into account the degradation of the concrete shear resisting mechanisms due to cyclic loading in the inelastic range.

\section{ACKNOWLEDGEMENTS}

The New Zealand National Society for Earthquake Engineering and the Earthquake commission are thanked for their financial assistance during the reconnaissance visit to Kobe. Mr Jeff Clendon of the Holmes Consulting Group, Christchurch, is thanked for the flexural strength and curvature analysis of the column sections.

\section{REFERENCES}

Japan Road Association, 1980. Seismic Design: Design Specifications for Highway Bridges.

Jennings, PC, Editor, 1971. Engineering Features of the San Fernando Earthquake, February 9, 1971, Earthquake Engineering Research Laboratory, California Institute of Technology.

King, D J, 1986. Computer Programs for Concrete Column Design, Master of Engineering Report, University of Canterbury.

Mander, J B, Priestley, MJN and Park, R, 1988. Theoretical Stress-Strain Model for Confined Concrete, Journal of Structural Engineering, American Society of Civil Engineers, Vol. 114, No. 8, pp 1804-1826.

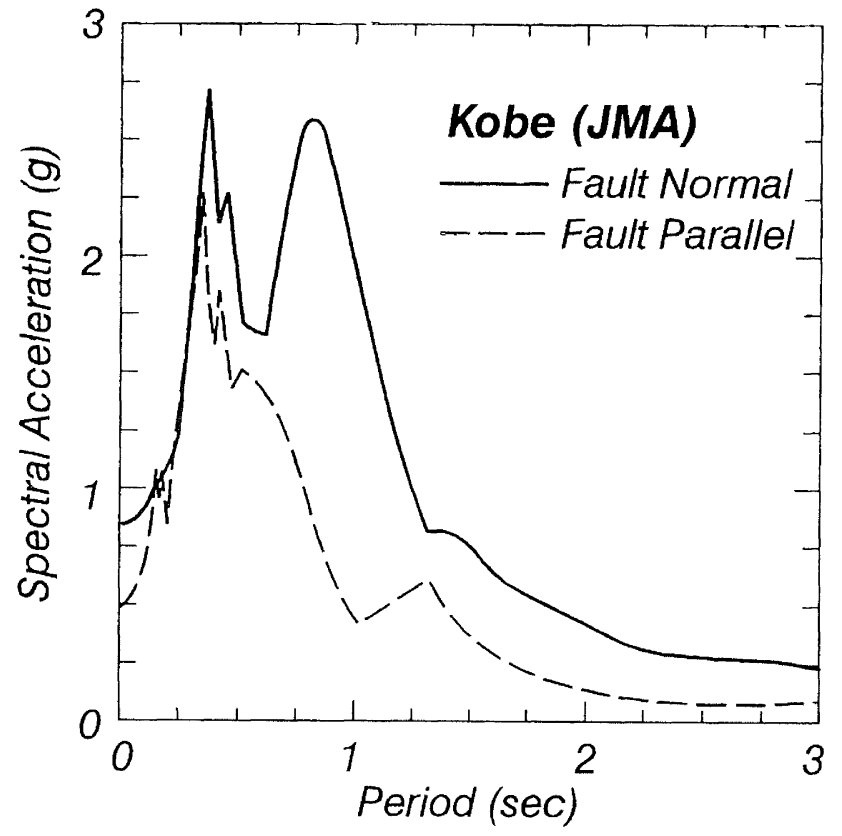

FIGURE 10 Elastic Response Spectral Acceleration Components Computed from Ground Motions Recorded at Kobe JMA Station [Somerville, 1996].

Park, R and Paulay, T, 1975. Reinforced Concrete Structures, John Wiley and Sons, New York.

Park, R, Billings, IJ, Clifton, GC, Cousins, J, Filiatrault, A, Jennings, DN, Jones, LCP, Perrin, ND, Rooney, SL, Sinclair, J, Spurr, DD, Tanaka, H and Walker, G, 1995. The Hyogo-ken Nanbu Earthquake (The Great Hanshin Earthquake) of 17 January 1995, Bulletin of the New Zealand National Society for Earthquake Engineering, Vol.28, No.1, March 1995, pp 1-98.

Priestley, MJN, Seible, F, Verma, R and Xiao, Y, 1993 Seismic Shear Strength of Reinforced Concrete Columns, University of California, San Diego, Structural Systems Research Project Report No. SSRP 91/06.

Priestley, MJN and Park, R, 1987. Strength and Ductility of Concrete Bridge Columns Under Seismic Loading, Structural Journal of the American Concrete Institute, Vol. 84, No. 1, pp 61-76.

Somerville, P, 1996. Forward Rupture Directivity in the Kobe and Northridge Earthquakes, and Implications for Structural Engineering, Seventh US-Japan Workshop on Improvement of Structural Design and Construction Practices, Lessons Learned from Kobe and Northridge, Kobe.

Standards New Zealand, 1995. Design of Concrete Structures NZS 3101:1995.

Watson, S and Park, R, 1994. Simulated Seismic Load Tests on Reinforced Concrete Columns, Journal of Structural Engineering, American Society of Civil Engineers, Vol. 120, No. 6, pp 1825-1849. 